\title{
Alegoria e (anti)bucolismo: da clivagem entre a poesia pastoral greco- latina e as pastorelas alegóricas médio-latinas
}

\author{
Henrique Marques Samyn \\ Universidade do estado do Rio de Janeiro \\ trovares@yahoo.com.br
}

\begin{abstract}
In this article, we attempt to analyse the medieval Latin pastourelles in contrast with the pastoral poetry of the bucolic tradition. We analyse three pastourelles of the Carmina Burana, which in our interpretation have an allegorical meaning: Estivali sub fervore (CB 79), Lucis ordo sidere $(C B$ 157) and Vere dulci mediante ( $C B$ 158); we argue that the concept of counter-pastoral as defined by Raymond Williams can be useful to understand the representation of the country in medieval Latin pastourelles, though some reevaluation is necessary. Our conclusion is that the absence of the real social conditions of country life in medieval Latin pastourelles is deeply related to its allegorical content.
\end{abstract}

KEYWORDS: pastourelle; counter-pastoral; allegory; medieval Latin poetry; Carmina Burana.

\section{Introdução}

Um dos mais instigantes gêneros poéticos produzidos na Idade Média - tanto pela profusão de exemplares que produziu, em inúmeras variantes, disseminando-se por uma vasta extensão territorial, quanto pela pletora de questões que suscita em torno da literatura e da cultura medieval - é a pastorela, que pode ser caracterizada lato sensu como uma composição em versos que descreve o encontro entre uma pastora e um homem (em geral, um cavaleiro) num cenário campestre. Conquanto essa similaridade no tocante à ambiência possa sugerir, à primeira vista, uma relação genética entre a poesia pastoral greco-latina e as referidas obras medievais, uma investigação mais profunda revela que entre esses dois corpora há não só marcantes diferenças estruturais como também uma oposição naquilo que tange a elementos essenciais das composições clássicas. Será esse o nosso objeto de análise no presente artigo.

A fim de expor de modo claro nossa argumentação, estruturamos este texto em três etapas. Começamos apresentando uma breve revisão bibliográfica sobre a hipótese, já algum tempo considerada obsoleta, da origem greco-latina das pastorelas medievais, o que permite atestar uma primeira clivagem entre essas e a tradição bucólica clássica. Num segundo momento, apresentamos uma definição do conceito de pastorela alegórica, a partir da qual efetuamos o recorte das pastorelas médio-latinas aqui tematizadas. Por fim, aprofundamos nossa análise utilizando o conceito de antibucolismo, emprestado do teórico galês Raymond Williams, que adaptamos para viabilizar nossa reflexão em torno do corpus mencionado. Tencionamos, desse modo, 
demonstrar em que medida consideramos que as referidas composições medievas podem ser qualificadas como antibucólicas - e, por conseguinte, como obras que podem ser contrapostas à poesia pastoral greco-latina.

\section{Das origens (não-latinas) das pastorelas medievais}

Ao longo do século XIII, a Europa conhece uma nova modalidade poética que se caracteriza não por padrões formais, mas por similaridades temáticas: são composições que invariavelmente retratam um ambiente campestre e descrevem o encontro entre uma pastora e um homem que tenta seduzi-la - às vezes, apenas com palavras galantes; outras vezes, ofertando presentes ou fazendo promessas de casamento. Os desfechos para esses enredos são igualmente variáveis: ora favorecem a pastora, que então consegue rechaçar as investidas do sedutor - o que eventualmente enseja situações de burla; ora atribuem a vitória ao sedutor, que então acaba por possuir a pastora - ainda que, em certos exemplares, faça-o através da violência. Há pastorelas em que é possível vislumbrar um final que favorece tanto a pastora quanto o homem que a seduz: é quando a pastora, tendo aceitado os presentes ou cedido às palavras daquele que a interpelava, entrega-se a ele num ato amoroso. Existem, finalmente, pastorelas que envolvem outros personagens além dos já mencionados: por vezes, esse terceiro elemento é Robin, nome mais comum do namorado ou noivo da pastora; há, também, casos em que aparecem animais ou grupos de pastores, cuja influência pode determinar diversos tipos de desfechos. Cabe reiterar ainda que há uma nítida diferença entre as pastorelas médio-latinas e as composições medievais pseudo-vergilianas, sendo as primeiras claramente influenciadas pelos modelos vernaculares em que se fazem presentes os elementos supracitados; retornaremos a esse ponto mais adiante.

$\mathrm{O}$ fato de a Antiguidade haver produzido poesias que retratavam cenários campestres sugeriu a vários teóricos e historiadores da literatura uma possível relação entre aquelas obras e as pastorelas medievais. Um dos principais proponentes dessa teoria, na década de 1920, foi o medievalista francês Edmond Faral. Ocorre que a pastorela mais antiga documentada é L'autrier jost'una sebissa, composta pelo trovador occitânico Marcabru entre 1130 e 1149, período que delimita sua atividade literária; não obstante, a brevíssima Vida de um outro trovador occitânico, Cercamon - aliás, contemporâneo de Marcabru - afirma que esse trovador da Gasconha "compôs versos e 
pastorelas à maneira antiga" (trobet vers e pastoretas a la usanza antiga) ${ }^{1}$. Faral $^{2}$ postulou que essa passagem faria alusão a pastorelas eventualmente derivadas das composições bucólicas pseudo-vergilianas criadas na Idade Média; desse modo, supôs que a expressão "à maneira antiga" deveria ser lida como "à maneira dos antigos", havendo nela portanto uma referência aos autores clássicos. A fim de fundamentar essa hipótese, Faral constatou que, tanto nas pastorais de extração vergiliana quanto nas pastorelas, certos personagens são nomeados: Títiro e Melibeu, nas composições antigas; Robin e Perrin, nas medievais. Ademais, numas e noutras os personagens fazem-se acompanhar por animais correspondentes às suas posses, como cães ou ovelhas; as descrições apresentam-nos com seus cajados e, não raro, instrumentos musicais, fazendo também menção à sua comida e às suas vestimentas. Por fim, em ambos os casos o discurso é atravessado por uma retórica cujo principal fim é ressaltar a simplicidade da situação descrita.

Todavia, essa argumentação de Faral é insuficiente: como objetou William Jones, ${ }^{3}$ ela apenas permite inferir que, tanto em umas quanto em outras, os poemas tematizam a vida pastoral. Além disso, aquilo que Faral apresenta como o argumento mais convincente em favor de sua hipótese - uma bucólica da tradição pseudovergiliana composta pelo poeta britânico Johannes de Garlandia (c.1190 - c.1270) apresenta nítidos problemas tanto no tocante à datação, já que data do segundo quarto do século XIII (sendo, assim, bastante posterior às pastorelas francesas e occitânicas), quanto em relação ao conteúdo, sendo possível apenas vagamente aproximá-la das pastorelas vernaculares que, mais tarde, inspirariam os exemplares médio-latinos.

Um dos primeiros críticos das hipóteses de Faral foi o filólogo belga Maurice Delbouille, que apresentou uma teoria diversa sobre as pastorelas, relacionando-as a certas composições médio-latinas datadas do século XII - mais especificamente, a um conjunto de obras da escola poética de Ripoll que haviam sido resgatadas por Lluis Nicolau D’Olwer pouco antes da publicação do ensaio de Delbouille. Defendia o belga a ideia de que as pastorelas não portavam um lirismo amoroso de extração clássica, mas um erotismo de tons goliárdicos, sendo possível aproximá-las de outras obras médiolatinas - os Carmina Cantabrigiensia e os Carmina Burana - a partir de elementos

\footnotetext{
${ }^{1}$ Cf. De Riquer, M. Los trovadores. Historia literaria y textos. Barcelona: Ariel, 2001. Tomo I, p. 222 (minha tradução).

${ }^{2}$ Cf. Faral, E. La pastourelle. Romania. Paris, vol. XLIX, p. 242, 1923.

${ }^{3}$ Cf. Jones, W. P. Some recent studies on the Pastourelle. Speculum. Cambridge, vol. V, n. 2, p. 210 , abr. 1930.
} 
como a ambiência pastoral, o diálogo amoroso e a temática erótica. Também no texto de Delbouille não encontramos, contudo, um argumento que comprove cabalmente a existência de uma relação entre as pastorelas e as composições médio-latinas; é o próprio filólogo quem o admite quando, ao analisar comparativamente com as pastorelas um dos textos da escola de Ripoll, De somnio, reconhece haver "grandes diferenças" entre essa e aquelas, conquanto insista - algo contraditoriamente - na existência de "grandes afinidades" entre uma e outras. ${ }^{4}$

As dificuldades de sustentação da hipótese de uma origem greco-latina para as pastorelas foi apresentada de modo claro por Frederic Raby que, numa série de textos diferentes publicados no início da década de $1930^{5}$ - portanto, na década seguinte àquela em que vieram à luz as conjeturas de Faral e de Delbouille - apresentou fortes argumentos contra aqueles que sustentavam essa teoria. Tendo como alvo principal o medievalista Hennig Brinkmann, que situava a cultura clerical e latina na origem da poesia occitânica e germânica, ${ }^{6}$ Raby amparou-se em objeções de cunho formal para refutar a ideia de que a lírica secular médio-latina seja anterior à vernacular: consoante Raby, as formas de versificação utilizadas na poesia vernácula raramente são aquelas presentes na versificação litúrgica em língua latina; o que aconteceu foi, no sentido inverso, uma adaptação da versificação latina a um conjunto de estruturas absorvidas das canções vernaculares. ${ }^{7}$

A influência da cultura vernácula sobre a médio-latina, no entanto, torna-se ainda mais clara no tocante aos temas e à ambiência presente nas composições. Durante toda a Idade Média, afirma Raby, é possível perceber um amplo uso de temas derivados da cultura vernácula sobre a lírica médio-latina, tanto temas populares quanto "literários"; apenas a compreensão dessa influência permite uma compreensão adequada dos motivos explorados pelos poetas médio-latinos. Cabe considerar a provável hipótese de que as pastorelas de Walter de Châtillon, assim como aquelas dos Carmina Burana, sejam derivadas de modelos literários prévios: a ideia de que a poesia latina tenha uma

\footnotetext{
${ }^{4}$ Cf. Delbouille, M. Les origines de la pastourelle. Mémoire présenté le 7 décembre 1925 à la classe des Lettres et des Sciences morales et politiques. Bruxelles: Maurice Lamertin, 1926, p. 29-39.

${ }^{5}$ Cf. Raby, F. J. E. Resenha de: Gaselee, S. The transition from the late latin lyric to the medieval love poem (Cambridge: Bowes and Bowes, 1931). The Classical Review. Cambridge, vol. XLVI, n. 3, p. 142143, jul. 1932/ 204-208, abr.1933/ . Surgens Manerius summo diluculo... Speculum. Cambridge, vol. V, n. 2, p. Press, 1934. 2 vol.

${ }^{6}$ Cf. Brinkmann, H. Geschichte der lateinischen Liebesdichtung im Mittelalter. Halle: M. Niemeyer, 1925./ Entstehungsgeschichte des Minnesangs. Halle: M. Niemeyer, 1926.

${ }^{7}$ Cf. Raby, op. cit., 1934, vol. II, p. 337.
} 
prioridade e preeminência sobre as outras é equivocada, mormente por ser uma propriedade de homens eruditos; sua grande virtude é o fato de ela haver buscado amparo fora das escolas e da retórica escolástica, ${ }^{8}$ sendo assim capaz de renovar-se. Não obstante, o afastamento das hipóteses que postulavam origens latinas para as pastorelas medievais não significa que uma resposta definitiva tenha sido encontrada para o questionamento em torno do surgimento daquele gênero poético. ${ }^{9}$

\section{As pastorelas alegóricas médio-latinas}

A já mencionada obra do trovador occitânico Marcabru L'autrier jost'una sebissa é um dos dois principais modelos a partir dos quais as pastorelas medievais se desenvolveriam; a esse modelo occitânico se opõe um outro modelo, de origem francesa, sendo que uma das mais marcantes diferenças entre esses dois tipos de pastorelas diz respeito ao assunto que especificamente nos interessa: a dimensão alegórica das pastorelas occitânicas.

A pastorela de Marcabru descreve um encontro, num cenário campestre próximo de uma sebe (jost'una sebissa ${ }^{10}$ ), entre um cavaleiro e uma pastora vestida rusticamente - o que, aliás, explicita sua baixa condição social. Ao longo de treze estrofes, Marcabru constrói um diálogo em que a pastora refuta, com astuciosos argumentos, as maliciosas investidas retóricas do narrador, até que, finalmente, o cavaleiro dá-se por vencido; a pastora encerra o colóquio com palavras moralizantes: "um tal se embevece com a pintura,/ enquanto o outro espera pelo maná!” (“Que tals bad' en la peintura/ Qu'autre n'espera la mana!'), assim condenando a sensual atitude do narrador - para quem apenas a aparência importa - e reafirmando sua própria força moral: símbolo de origem bíblica, o maná representa o alimento divino, constituindo portando um índice das aspirações morais da pastora. ${ }^{11}$

Diversas são as observações que podem ser feitas sobre a obra de Marcabru, mormente acerca da pouco verossimilhante situação nela descrita: um cavaleiro

\footnotetext{
${ }^{8}$ Cf. Raby, op. cit., p. 337-338.

${ }^{9}$ Sendo esse um dos temas de nossa atual pesquisa de doutorado, a hipótese (não-conclusiva) à que chegamos é de que a pastorela medieval nasceu a partir de dois modelos autóctones diferentes, um occitânico e um francês, que se desenvolveram de forma mais ou menos independente a partir de origens folclóricas; esses dois modelos originaram diversos exemplares em outras línguas, dentre os quais a latina. Abordaremos essa questão no próximo item deste artigo.

${ }^{10}$ Todas as citações do texto occitânico são da edição de Audiau (La pastourelle dans la poésie occitane du Moyen Âge. Paris: E. de Boccard, 1923, p. 3-9). As traduções são minhas.

${ }^{11}$ O maná também se faz presente na obra de outro trovador occitânico, Jaufré Rudel, igualmente suscitando interpretações de sentido religioso (cf. Frank, G. The distant love of Jaufré Rudel. Modern language notes. Maryland, vol. LVII, n. 7, p. 532-533, nov. 1942).
} 
medieval que desejasse possuir uma jovem bela e solitária com que se deparasse durante uma jornada pelo campo dificilmente estaria disposto a sustentar longos debates retóricos com ela; por outro lado, ainda que o fizesse, como crer que uma humilde jovem tivesse condições para rebater tão habilmente os argumentos de um homem de origem nobre, numa época em que a maioria das camponesas não recebia qualquer educação, exceto por alguns rudimentares conhecimentos religiosos? ${ }^{12} \mathrm{~A}$ indagação que cabe fazer é: não haveria um sentido latente sob essa superfície textual, algo que possibilite uma leitura da obra como representação de um outro tipo de confronto - ou, em outras palavras: não se destina o texto menos à descrição de uma situação supostamente real do que à apresentação de um questionamento alegórico?

De fato: um cotejo entre os exemplares das tradições autóctones de pastorelas medievais - a occitânica e a francesa - revela que nas primeiras é frequente o uso da simbologia religiosa, ao passo que nos exemplares franceses deparamo-nos com situações mais verossimilhantes, conquanto não se trate propriamente de falar em termos de um "realismo" literário. Não obstante, nas pastorelas francesas há cavaleiros que não hesitam ao lançar mão da violência para possuir as jovens pastoras que encontram em seu caminho, assim como diversas delas cedem aos galanteios amorosos - e promessas - dos nobres com que se deparam; em oposição a isso, os exemplares occitânicos comumente descrevem pastoras que se declaram dispostas a viver dedicando-se aos princípios cristãos, eventualmente chegando a trajar-se à maneira de membros de ordens religiosas, ${ }^{13}$ o que as coloca numa posição diametralmente oposta à dos sedutores: trata-se de um embate entre virtude e o vício, entre a pureza e o pecado, entre o espírito e a sensualidade.

Além desse sentido alegórico-moralizante, as pastorelas derivadas da tradição occitânica estabelecida a partir de Marcabru possuem as cinco características do modelo

\footnotetext{
${ }^{12}$ Cf. Power, E. Medieval women. New York: Cambridge University Press, 1997, p. 78/ Shahar, S. The fourth Estate. A history of women in the Middle Ages. Tradução de Chaya Galai. London: Metheun, 1983, p. 248.

${ }^{13}$ Evidentemente, o que aqui apresentamos são apenas traços gerais de cada um desses modelos de pastorelas, cabendo observar que há variantes tanto no grupo occitânico quanto no francês. É certo, contudo, que o modelo alegorizante de pastorela criado por Marcabru encontra no âmbito occitânico um espaço para seu fortalecimento, dado que $47,8 \%$ das composições registradas desse corpus seguem de perto esse modelo; por outro lado, há ampla bibliografia sobre os aspectos eróticos e satíricos das pastorelas francesas. Sobre a origem das pastorelas alegóricas, cf. Samyn (Sobre as origens de um gênero poético medieval. A pastorela. In: Atas da VII Semana de Estudos Medievais do Programa de Estudos Medievais da UFRJ. Rio de Janeiro: Programa de Estudos Medievais, 2008); uma perspectiva tradicional sobre as diferenças entre as pastorelas francesas e occitânicas pode ser encontrada em Jones (The Pastourelle. Cambridge: Harvard University Press, 1931).
} 
clássico definido pelo teórico estadunidense William Paden, a saber: a ambiência pastoral; a presença de um homem e uma mulher; o contexto de encontro acidental e tentativa subseqüente de sedução; a mescla de narrativa e diálogo; e o ponto de vista masculino. ${ }^{14}$ No âmbito médio-latino, deparamo-nos com obras que respeitam esse conjunto de critérios no corpus conhecido como Carmina Burana, sendo três as pastorelas que podem ser classificadas como alegóricas: Estivali sub fervore ( $C B$ 79), Lucis ordo sidere $\left(C B\right.$ 157) e Vere dulci mediante $(C B 158) .{ }^{15}$ Nos próximos parágrafos, apresentaremos uma síntese das referidas composições.

Em Estivali sub fervore ( $C B$ 79), o poeta-narrador depara-se, num ensolarado cenário estival, com uma pastorinha à qual atribui singular beleza; aproximando-se da jovem, seguramente já antecipando uma reação negativa, procura mostrar-se amistoso, chamando-a para junto de si e assegurando não ter qualquer intenção malevolente, gesto em que já se pode entrever uma intenção sedutora: “"Venhas!' ... 'Não sou salteador,/ nada roubo, ninguém firo"” (“'ades!' ... 'non sum predo, / nichil tollo, nichil ledo'."16); segue-se a isso a tentativa concreta de sedução, quando o narrador se oferece por inteiro à pastora, além de tudo o que possui: "A ti me entrego, e tudo o que eu tenho" (me meaque tibi dedo). A jovem, contudo, apressa-se a rejeitar a aproximação do narrador: sugere que é virgem - "Não cresci habituada às brincadeiras masculinas" -, manifesta receio de ser castigada por seus pais - principalmente por sua velha e colérica mãe - e, por fim, roga ao cavaleiro: "Não me faça mal agora" (“"ludos viri non assuevi./ sunt parentes michi sevi:/ mater longioris evil irascetur pro re levi./ parce nunc in hora."'). O fato de essa rejeição encerrar o poema não deve ser entendido como índice de

\footnotetext{
${ }^{14}$ Cf. Paden, W. D. New thoughts on an old genre. The pastorela. Romance languages annual. [s.1.], vol. X, p. 111-112, 1999.

${ }^{15}$ A síntese aqui apresentada de Estivali sub fervore ( $C B$ 79) com Vere dulci mediante ( $C B$ 158) é um resumo da que apresentamos em Samyn, 2007, artigo onde também tratamos de outro ponto relevante: as semelhanças formais e temáticas perceptíveis através de um cotejo entre essas duas pastorelas pode levar à suspeita de que tenham sido compostas pelo mesmo autor. Levantamos essa possibilidade a partir dos elementos que ora sintetizamos: tanto $C B 79$ quanto $C B 158$ possuem seis estrofes, cada qual com seis versos; em cada estrofe, os cinco primeiros versos possuem a mesma rima, e a o verso final rima com os versos finais de todas as outras cinco estrofes (seguem, portanto, este mesmo esquema, índice de virtuosismo: AAAAAB/ CCCCCB/ DDDDDB/ EEEEEB/ FFFFFB/ GGGGGB). As semelhança temática está relacionada ao fato de serem raras as pastorelas entre os Carmina Burana: Michel Zink (La Pastourelle. Poésie et folklore au Moyen Age. Paris: Bordas, 1972, p. 35-36) elenca dez, mas uma seleção mais rigorosa enumera apenas quatro ou cinco [cf. Jones, op. cit., 1931/ Walsh, P. G. (org.) Love lyrics from the Carmina Burana. Edited and translated with a commentary by P. G. Walsh. North Carolina: The University of North Carolina Press, 1993]. De resto, há uma notável consistência no desenvolvimento das estórias narradas nesses dois carmina.

${ }^{16}$ Citamos a partir da edição de Walsh (cf. op. cit., 1993). As traduções são minhas.
} 
incompletude, na esteira de Schumann, ${ }^{17}$ visto ser esse um desfecho comum às pastorelas; trata-se antes de um recurso literário que visa ressaltar o sentido moralizante do discurso da pastora, em oposição às maliciosas intenções da figura masculina. Cabe levar em consideração o comentário de Peter Dronke, ${ }^{18}$ de acordo com o qual o acréscimo de mais estrofes arruinaria esse clímax que enfoca as emoções da pastora. De resto, o que temos aí é uma situação de conflito: de um lado encontra-se o narrador, cuja lascívia é denunciada por sua apreciação da beleza da jovem; de outro lado encontra-se a pastora, uma figura fragilizada, de traços infantis - o que se deve sobretudo à menção ao castigo dos pais e à referência às "brincadeiras masculinas" que a jovem afirma desconhecer.

Lucis ordo sidere $(C B$ 157) é a pastorela mais instigante entre as que comparecem nos Carmina Burana, visto que apresenta um elemento estranho às pastorelas occitânicas - a figura do lobo, comum nas pastorelas francesas -, mas que é na obra inteiramente ressignificado. A composição inicia-se quando o narrador, num cenário primaveril, depara-se com uma pastora que conduz um rebanho de ovelhas. Quando a jovem, a fim de proteger-se do sol, refugia-se sob uma árvore, o narrador aproveita para aproximar-se, solicitando o seu favor: "Saudações, digna de um rei!/ Ouve, rogo, este servo,/ e haverás de ser gentil para comigo!" (“"salve, rege digna!/ audi, queso, servulum,/ esto michi benigna!'”). A pastora rejeita-o, declarando que jamais conheceu homem nenhum; é quando surge um lobo, que rouba uma das ovelhas do rebanho. Em desespero, a pastora grita: “Aquele que resgatar a [minha] ovelha/ terme-á por esposa!” (“"si quis ovem redderet/ me gaudeat uxore!'”). A última estrofe, no entanto, apresenta um desfecho surpreendente: o narrador desembainha a espada e mata o lobo; não obstante, os últimos versos focalizam a ovelha, que é assim redimida da morte ("ovis ab exitio/ redempta reportatur"). A obra é de intepretação difícil; cabe mencionar que o uso de um léxico e de expressões com ressonâncias teológicas sugeriu a Patrick Walsh que essa é uma obra que deve ser lida a partir de uma perspectiva religiosa, onde o narrador é uma representação crística e, a pastora, uma alegoria composta da Igreja e da Virgem. ${ }^{19}$ De todo modo, a cena descrita na estrofe final não

\footnotetext{
${ }^{17}$ Cf. Hilka, A.; Schumann, O. Carmina Burana. Mit Benutzung der Vorarbeiten Wilhelm Meyers, kritisch herausgegeben von Alfons Hilka und Otto Schumann. Heildelberg: Carl Winter's Universitätbuchhandlung, 1941. I Band: Text - 2: Die Liebeslieder - Herausgegeben von Otto Schumann, p. 61.

${ }_{18}$ Cf. Dronke, P. The medieval poet and his world. Roma: Edizioni di Storia e Letteratura, 1984, p. 265.

${ }^{19}$ Cf. Walsh, P. G. "Pastor" and pastoral in Medieval Latin poetry. In: Cairns, F. (org.). Papers of the
} 
deixa dúvidas a respeito da condição alegórica da obra.

Em Vere dulci mediante ( $C B$ 158), o narrador se encontra num cenário primaveril quando se vê diante de uma jovem cuja beleza, em seu julgamento, supera a de todas as ninfas; ao vê-lo, a garota grita e se refugia num curral de ovelhas, sendo perseguida pelo narrador, que lhe roga: “Acalme-se!/ Não temas nada ruim!” (“[...] sile!/ nichil timeas hostile!'). Em seguida, o narrador inicia uma tentativa de sedução, estendendo à pastora um colar; ela, no entanto, recusa-o, entrevendo no gesto veladas intenções: "Vosso presente [...] não quero, porque está cheio de ardis!” (“"Munus vestrum', inquit, 'nolo,/ quia pleni estis dolo!'”). Não obstante, o narrador não aceita a recusa da pastora, e não hesita em empregar a violência. A pastora tenta defender-se, usando seu pequeno bastão de fiar; todavia, o sedutor domina-a - e a dor da jovem apenas amplia o prazer masculino ("Satis illi fuit grave,/ michi gratum et suave."). Nos dez versos finais, a obra adquire um forte tom moralizante quando a pastora lamenta não por si, mas por seu violador: “'O que fizeste’, disse, 'perverso!/ Ai, ai de ti! Mesmo assim, fique em paz!'” (“"quid fecisti', inquit, 'prave!/ ve ve tibi! tamen ave!’”); a jovem revela-se, portanto, capaz de amar aquele que a ofendeu, em que podemos entrever a caritas cristã. Encerra-se a pastorela com um desfecho comum nas pastorelas: a pastora roga ao narrador que mantenha em segredo o que ocorreu, para que ela não seja punida em casa.

Nas três pastorelas presentes nos Carmina Burana encontramos, portanto, todas as características próprias das pastorelas alegóricas, o que é um claro indício de que foram certamente influenciadas pelo modelo de Marcabru. Conquanto já tenha sido aventada, a hipótese de uma influência no sentido contrário não deve ser estimulada, por razões pragmáticas (a ausência de dados históricos a seu favor amplia consideravelmente o labor para a sua sustentação) e por uma questão de bom senso (já que cabe levar em conta a observação já transcrita de Raby, acerca da absorção de temas da literatura vernácula pela médio-latina); ademais a pastorela, enquanto gênero, disseminou-se por toda a Europa durante a Idade Média - e não havia motivo para que os autores médio-latinos não procurassem, de algum modo, dialogar com esses modelos literários, assim como fizeram com diversos outros.

\section{Do antibucolismo médio-latino}




\section{nuntius antiquus}

Alcançamos, enfim, o momento final de nossa reflexão, em que tencionamos analisar uma questão específica, a saber: a clivagem existente entre as pastorelas medievais e a poesia pastoral clássica no tocante às suas formas de representação do campo. Para viabilizar esse questionamento, utilizaremos o conceito de antibucólico, cunhado pelo teórico galês Raymond Williams em seu estudo acerca das representações literárias do campo e da cidade. ${ }^{20}$ Cabe ressaltar que, na verdade, Williams emprega o referido conceito para a análise de um contexto bastante diverso dos que nos interessa: seu objeto era resistência da poesia inglesa de fins do século XVII ao bucolismo clássico e neoclássico, já que aquela tinha pretensões de retratar o campo de forma mais "realista".

Poetas como George Crabbe sustentavam que o bucolismo só podia ser propriamente fundamentado na Antiguidade clássica, cabendo então optar por uma representação diversa do campo, enquanto refúgio simultaneamente real e metafórico, ${ }^{21}$ consoante Williams, é possível entrever aí uma grave questão política: por trás da celebração da exuberância natural, ocultava-se a exploração do trabalho dos camponeses. $^{22}$ Evidentemente, o objeto de estudo do teórico galês dista séculos do nosso; não se trata aqui de empregar seu conceito de forma integral, mas antes de extrair dele o que pode ser pertinente para a nossa análise. Nessa medida, o conceito de antibucolismo tem para a nossa investigação o valor de, por um lado, encerrar uma mudança essencial no modo de representação do campo no espaço literário e de, por outro, estabelecer uma articulação entre essa transformação e um conjunto de elementos literários; por conseguinte, trata-se de compreender a oposição entre o antibucólico e o bucólico mediante o contraste que o primeiro estabelece em relação ao último a partir de um conjunto de elementos que ultrapassam o âmbito literário. Não obstante, antes de aplicar o conceito à nossa reflexão sobre as pastorelas médio-latinas, cabe recuperar alguma informação sobre o bucolismo clássico.

Há um consenso geral em torno da ideia de que os princípios da poesia bucólica devem ser buscados nos Idílios de Teócrito (séc. III AEC), obra que teve uma influência determinante na poesia de Vergílio - sendo esse, por sua vez, autor do conjunto de poemas que constituiria a pedra fundamental da tradição bucólica latina: as Éclogas (c.

\footnotetext{
${ }^{20}$ Cf. Williams, R. Bucólico e antibucólico. In: O campo e a cidade. Na história e na literatura. Tradução de Paulo Henriques Britto. São Paulo: Companhia das Letras, 1989.

${ }^{21}$ Cf. Williams, op. cit., p. 40.

${ }^{22}$ Cf. Williams, op. cit., p. 52.
} 
42-37 AEC). Concentraremos nossa exposição nessas obras, mais representativas da tradição bucólica antiga.

Em linhas gerais, os Idílios de Teócrito são um conjunto de poemas pastorais que tratam da vida campestre na Sicília. Conquanto autores como Harvey ${ }^{23}$ caracterizem os Idílios como naturalistas, a via analítica que enfatizava na mencionada obra qualidades como a simplicidade e o naturalismo encontra hodiernamente resistência, sobretudo por teóricos que a qualificam como complexa e artificialista. ${ }^{24}$ Não sendo esse o nosso escopo, não aprofundaremos aqui esses questionamentos; interessa-nos, principalmente, a articulação das obras de Teócrito e de Vergílio enquanto constitutiva do que podemos designar tradição bucólica clássica, o que implica rastrear aproximações e afastamentos em busca de elementos ressaltantes.

Os Idílios teocritianos, investindo em temas como as disputas de canto entre os camponeses (Idílio V), suas conversas durante o trabalho (Idílio IV) ou suas canções sobre motivos mitológicos (Idílio I), constituem um projeto literário por meio do qual logra o poeta erigir um novo discurso a partir de elementos genéricos pré-existentes; se isso, por um lado, confere-lhes um aspecto de incompletude, ${ }^{25}$ por outro lado os Idílios revelam uma inovação e uma revalorização de formas então reputadas inferiores. ${ }^{26}$ Também a obra de Vergílio constitui um empreendimento inovador: o poeta latino não emula Teócrito, mas extrai dos Idílios motivos que utiliza para a criação de obras marcadas por um estilo pessoal diverso que, ademais, inscrevem-se num âmbito histórico e cultural muito diferente daquele em que o vate grego produziu sua obra. Não obstante, há quem veja na obra de Vergílio um amaneiramento maior do que aquele perceptível nos poemas de Teócrito: conquanto não seja o caso de retornar à argumentação que se balizava por um suposto "realismo", percebe-se no texto vergiliano uma interferência maior de elementos da convenção e da fantasia na representação da ambiência pastoral. ${ }^{27}$

Essas disparidades são alvo da leitura de Raymond Williams, que entrevê nos poemas teocritianos a representação de uma comunidade camponesa cujo gozo das

${ }^{23}$ Cf. Harvey, P. Dicionário Oxford de literatura clássica. Tradução de Mário da Gama Kury. Rio de Janeiro: Zahar, 1987, p. 481.

${ }^{24}$ Essa questão é discutida por Van Sickle (Is Theocritus a version of Pastoral? Modern language notes. Maryland, vol. LXXXIV, n. 6, p. 942-946, dez. 1969), entre outros.

${ }^{25}$ Cf. Gutzwiller, K. J. Theocritus' pastoral analogies. The formation of a genre. Madison: University of Wisconsin Press, 1991, p. 8-9.

${ }^{26}$ Cf. Hunter, R. L. Theocritus. A selection. New York: Cambridge University Press, 1999, p. 2.

${ }^{27}$ Cf. Mendes, J. P. Construção e arte das “Bucólicas” de Virgílio. Coimbra: Almedina, 1997, p. 124126. 
paisagens férteis e estivais está relacionado a uma aguda percepção da esterilidade e das dificuldades do inverno; esse esforço em prol da tranformação literária das condições sociais da vida campestre não é pedido na poesia vergiliana. ${ }^{28}$ Desse modo, podemos considerar que toda a poesia bucólica tem como eixo um conjunto de modos concretos de relação com a vida rural que determinam diferentes formas de representação literária, sendo essas constituídas ao longo de um processo histórico; e o fato de os poetas bucólicos clássicos, desde seu antecessor Hesíodo até Vergílio, terem convivido de perto com a realidade dos camponeses - o que é um fato no caso dos dois mencionados e postulado no caso de Teócrito ${ }^{29}$ - certamente favorece essa leitura.

Não obstante, nada disso pode ser aplicado às pastorelas alegóricas médiolatinas. ${ }^{30} \mathrm{O}$ que nelas encontramos é uma ambiência campestre derivada de elementos meramente convencionais, onde a representação do campo já não guarda quaisquer relações determinantes com as condições concretas da vida rural; trata-se, em outras palavras, de um tópos literário construído, enquanto tal, no âmbito da própria tradição poética. Por outro lado, isso não significa que essa clivagem presente nas pastorelas médio-latinas deva ser censurada, mormente pelo fato de nelas estar em jogo uma questão diversa, a saber: o investimento alegórico que anteriormente analisamos, em que o subjacente propósito moralizante opera como eixo da composição. Para dizer de outro modo: as pastoras que encontramos nas pastorelas dos Carmina Burana não são nem tencionam ser - representações fiéis de pessoas historicamente reais, o que se torna nítido a partir de um exame, mesmo que superficial, daquelas obras literárias; e é precisamente essa ausência de verossimilhança o que lhes permite desempenhar o que delas é exigido enquanto figuras alegóricas.

Cabe rechaçar, finalmente, uma série de compreensões equivocadas: não compete julgar as pastorelas alegóricas a partir de critérios supostamente realistas que as qualificariam como decadentes perante a verossimilhança dos exemplares franceses; tampouco cabe considerar que sua condição antibucólica - que se reflete no esvaziamento do campo enquanto literariamente constituído a partir das experiências concretas, sem que seja necessário postular parâmetros "realistas" - represente qualquer

\footnotetext{
${ }^{28}$ Cf. Williams, op. cit., p. 29-34.

${ }^{29}$ Wendell Clausen ("Theocritus and Virgil". In: Kenney, E. J. The Cambridge history of classical literature. Latin Literature. Part 3: The age of Augustus. New York: Cambridge University Press, 1983, p. 5), por exemplo, postula que Teócrito escreveu sua poesia bucólica movido pela nostalgia de uma infância passada entre os pastores da Sicília.

${ }^{30} \mathrm{Na}$ verdade, essa observação pode ser estendida retroativamente até as pastorelas alegóricas occitânicas a partir das quais o modelo foi constituído.
} 
tipo de perda relativamente à tradição clássica. O antibucolismo das pastorelas alegóricas médio-latinas deve ser compreendido como produto histórico de condições específicas, e é por essas condições que se deve indagar a fim de se compreender a emergência desse singular gênero poético no âmbito medieval.

\section{Referências}

AUDIAU, J. La pastourelle dans la poésie occitane du Moyen Âge. Paris: E. de Boccard, 1923.

BRINKMANN, H. Geschichte der lateinischen Liebesdichtung im Mittelalter. Halle: M. Niemeyer, 1925.

. Entstehungsgeschichte des Minnesangs. Halle: M. Niemeyer, 1926.

CLAUSEN, W. V. "Theocritus and Virgil". In: KENNEY, E. J. The Cambridge history of classical literature. Latin Literature. Part 3: The age of Augustus. New York: Cambridge University Press, 1983.

DE RIQUER, M. Los trovadores. Historia literaria y textos. Barcelona: Ariel, 2001. Tomo I.

DELBOUILLE, M. Les origines de la pastourelle. Mémoire présenté le 7 décembre 1925 à la classe des Lettres et des Sciences morales et politiques. Bruxelles: Maurice Lamertin, 1926.

DRONKE, P. The medieval poet and his world. Roma: Edizioni di Storia e Letteratura, 1984.

FARAL, E. La pastourelle. Romania. Paris, vol. XLIX, p. 204-259, 1923.

FRANK, G. The distant love of Jaufré Rudel. Modern language notes. Maryland, vol. LVII, n. 7, p.528-534, nov. 1942.

GUTZWILLER, K. J. Theocritus' pastoral analogies. The formation of a genre. Madison: University of Wisconsin Press, 1991.

HARVEY, P. Dicionário Oxford de literatura clássica. Tradução de Mário da Gama Kury. Rio de Janeiro: Zahar, 1987.

HILKA, A.; SCHUMANN, O. Carmina Burana. Mit Benutzung der Vorarbeiten Wilhelm Meyers, kritisch herausgegeben von Alfons Hilka und Otto Schumann. 
Heildelberg: Carl Winter's Universitätbuchhandlung, 1941. I Band: Text - 2: Die Liebeslieder - Herausgegeben von Otto Schumann.

HUNTER, R. L. Theocritus. A selection. New York: Cambridge University Press, 1999.

JONES, W. P. Some recent studies on the Pastourelle. Speculum. Cambridge, vol. V, n. 2, p. 207-215, abr. 1930.

The Pastourelle. Cambridge: Harvard University Press, 1931.

MENDES, J. P. Construção e arte das "Bucólicas” de Virgílio. Coimbra: Almedina, 1997.

PADEN, W. D. New thoughts on an old genre. The pastorela. Romance languages annual. [s.l.], vol. X, p. 111-116, 1999.

POWER, E. Medieval women. New York: Cambridge University Press, 1997.

RABY, F. J. E. Resenha de: GASELEE, S. The transition from the late latin lyric to the medieval love poem (Cambridge: Bowes and Bowes, 1931). The Classical Review. Cambridge, vol. XLVI, n. 3, p. 142-143, jul. 1932.

. Surgens Manerius summo diluculo... Speculum. Cambridge, vol. V, n. 2, p. 204-208, abr.1933.

. A history of secular latin poetry in the Middle Ages. Oxford: Clarendon Press, 1934. 2 vol.

SAMYN, H. M. As sortes da virtude. A alegoria em duas pastorelas dos "Carmina Burana" (CB 79 e CB 158). In: Idade Média. Permanência, atualização, residualidade. Anais do VII Encontro Internacional de Estudos Medievais. Fortaleza: 2007.

. Sobre as origens de um gênero poético medieval. A pastorela. In: Atas da VII Semana de Estudos Medievais do Programa de Estudos Medievais da UFRJ. Rio de Janeiro: Programa de Estudos Medievais, 2008.

SHAHAR, S. The fourth Estate. A history of women in the Middle Ages. Tradução de Chaya Galai. London: Metheun, 1983.

WALSH, P. G. "Pastor" and pastoral in Medieval Latin poetry. In: CAIRNS, F. (org.). Papers of the Liverpool Latin Seminar 1976. Liverpool: University of Liverpool, 1977. 


\section{nuntius antiquus}

commentary by P. G. Walsh. North Carolina: The University of North Carolina Press, 1993.

WILLIAMS, R. Bucólico e antibucólico. In:

O campo e a cidade. $\mathrm{Na}$ história e na literatura. Tradução de Paulo Henriques Britto. São Paulo: Companhia das Letras, 1989.

VAN SICKLE, J. B. Is Theocritus a version of Pastoral? Modern language notes. Maryland, vol. LXXXIV, n. 6, p. 942-946, dez. 1969.

ZINK, M. La Pastourelle. Poésie et folklore au Moyen Age. Paris: Bordas, 1972. 